\title{
UPORABNOST PROGRAMSKEGA ORODJA TOPOBASE PRI UPRAVLJANJU NEPREMIČNIN V OBRAMBNEM RESORJU
}

\section{USEFULNESS OF TOPOBASE SOFTWARE \\ IN PROPERTY MANAGEMENT OF THE DEFENCE SECTOR}

Povzetek Prispevek opisuje uvedbo sistema Topobase za podporo upravljanja objektov in infrastrukture na Letališču Cerklje ob Krki, ki bo uporaben tudi za vso drugo infrastrukturo in objekte v upravljanju Ministrstva za obrambo. Opisani so sistem Topobase kot integriran geografski informacijski sistem in poslovni informacijski sistem, podlaga oziroma potreba za uvedbo, namen in cilji sistema, definiranje zahtev, glavnih značilnosti in izbor sistema, pilotni projekt, vnos geoprostorskih in atributnih podatkov, nadgradnja osnovnega sistema z dodatnimi moduli, reševanje težav pri izvedbi ter dosedanji rezultati pri praktični uporabi. Predstavljena je učinkovita uporaba geoprostorskih podatkov na primeru uvajanja sistema Topobase na območju vojašnice in Letališča Cerklje ob Krki. Opisano je povezovanje s sedanjimi poslovnimi sistemi na MO. Opisan je vzrok, zakaj v poslovnih informacijskih sistemih za področje vzdrževanja infrastrukture potrebujemo georeferencirane podatke in moramo tem sistemom dodajati zunanji GIS-sistem.

Ključne

Vzdrževanje infrastrukture, upravljanje objektov, geoprostorska podpora, besede geografski informacijski sistem, prostorski podatki, prostorske analize, poslovni informacijski sistem, Topobase, AutoCAD Map 3D, Autodesk Infrastructure Map Server, Oracle Spatial.

Abstract The paper describes the introduction of a Topobase system to support the management of buildings and infrastructure at the Cerklje ob Krki Airport, which will also be useful for all other infrastructure and facilities managed by the Ministry of Defence. It describes the Topobase system as an integrated Geographic Information System and business information system; the basis or the need for its introduction; the purpose and objectives of the system; the definition of requirements, main characteristics and selection of the system; a pilot project; the introduction of geospatial and attribute data; an upgrade of the basic system with additional modules; troubleshooting in its 
implementation, and results so far in practical use. An effective use of geospatial data is presented in the case of the introduction of the Topobase system in the area of the barracks and the Cerklje ob Krki Airport. In addition, the article describes the integration with the existing business systems to the Ministry of Defence as well as the reason why in business information systems for infrastructure maintenance there is a need for geo-referenced data and why these systems must be complemented with an external GIS system.

Key words Infrastructure maintenance, facility management, geospatial support, Geographic Information System, spatial data, spatial analyses, business information system, Topobase, Auto CAD Map 3D, Autodesk Infrastructure Map Server, Oracle Spatial.

Uvod Upravljanje vseh objektov in pripadajoče infrastrukture v upravljanju Ministrstva za obrambo (v nadaljevanju MO) je organizacijsko in izvedbeno zahtevno. Upoštevati je treba tudi soodvisnost objektov in naprav ter njihovo kompleksnost in soodvisnost ljudi, ki izvajajo postopke. Vse to zahteva ustrezno organizacijo, ki obsega načrtovanje, usklajevanje, vodenje in izvedbo ter izvajalce, ki imajo razmejene pristojnosti in naloge.

Vzdrževanje objektov in infrastrukture na prvi pogled ne vključuje potrebe po GIStehnologiji, vendar nepogrešljivo potrebo po GIS $^{1}$ vidimo tako pri natančnejšem pregledu predpisanih postopkov vzdrževanja kot pri pregledu že uvedenih rešitev drugje. Večina tovrstnih rešitev namreč temelji na poslovnih informacijskih sistemih, ki se povezujejo na ločene GIS-sisteme. Slaba stran take »naveze« je, da uporabnik dela z najmanj dvema sistemoma za izvedbo ene naloge.

Prostorski podatki so za vladne in upravne inštitucije, komunalne, telekomunikacijske, inženirske in projektantske organizacije bistveni. Skoraj nujno je, da vsi našteti uporabljajo orodja za polno izrabo razpoložljivih podatkov in prostorskih informacij, ki so navadno shranjeni na različnih lokacijah, kot so osebni računalniki, spletni strežniki, datotečni strežniki, CAD-strežniki², GIS-strežniki itn. Posledica tega je, da se pojavlja redundanca podatkov. To je stroškovno problematična situacija, ko vsaka funkcionalna enota $v$ neki organizaciji na svoj način uporablja, shranjuje in upravlja iste podatke kot druge. Če bi vsi uporabljali podatke iz enega vira in jih tam tudi dopolnjevali, bi celotna organizacija prihranila čas in denar ter minimizirala ponavljajoča se opravila (Autodesk, Inc., 2010).

Uvedba sistema Topobase poteka v okviru projekta obnove Letališča Cerklje ob Krki. Investicija vključuje tudi IT-opremo za novo zmogljivost. Sistem deluje kot spletna aplikacija na internem omrežju MO. Dostopen je vsem zaposlenim, ki ga

\footnotetext{
Geografski informacijski sistem (kratica GIS, angl. Geographic(al) information system) je računalniško podprt podatkovni procesni sistem za učinkovito zajemanje, shranjevanje, vzdrževanje, obdelavo, analize, porazdeljevanje in prikazovanje prostorskih (geografskih) podatkov.

CAD - računalniško podprto načrtovanje ali računalniško podprto konstruiranje (v angleščini kratica CAD pomeni Computer Aided Design ali pa tudi Computer Aided Drafting) je ime za metode in postopke, skaterimi uporabimo računalnik kot pripomoček pri inženirskem delu.
} 
lahko uporabljajo znotraj spletnega brskalnika brez omejitve števila uporabnikov ali licenc, potrebna je le avtorizacija. Potek dela na projektu Topobase je bil predstavljen Slovenski vojski. Ugotovljena je funkcionalnost, ki presega vprašanja infrastrukture le na področju Letališča Cerklje. Sistem je kljub višji ravni zahtev zaradi zahtevnosti letališča uporaben tudi za vso drugo infrastrukturo in objekte v lasti MO, tako za vojaški kot za civilni del, ker so osnovni postopki vzdrževanja, ki so vgrajeni v ta sistem, predpisani z internimi izvedbenimi in nadrejenimi predpisi ter so identični tako za vojašnico z letališčem kot drugje.

$\mathrm{Na} \mathrm{MO}$ do zdaj ni bilo namenskega orodja za podporo vzdrževanju infrastrukture in objektov. Sedanji poslovni sistemi, ki že imajo nekatere primerne funkcionalnosti, do zdaj za področje vzdrževanja infrastrukture niso bili implementirani zaradi več vzrokov, na primer: pripraviti je treba podrobne tehnične zahteve in analize izvedljivosti v okviru danih zmogljivosti sistema, identificirati pomanjkljivosti in investirati $\mathrm{v}$ potrebne razširitve, prilagoditve, licence ipd. Sistem Topobase je prva tovrstna namenska rešitev na MO z vsebovano GIS-funkcionalnostjo, arhivom elektronske dokumentacije in vso potrebno poslovno funkcionalnostjo za načrtovanje, izvedbo, poročanje in nadziranje vzdrževanja.

\section{OSNOVNI OPIS SISTEMA TOPOBASE}

Sistem Topobase proizvajalca Autodesk, ki je eden največjih ponudnikov GISrešitev, v kupljenem paketu pokriva področje upravljanja gospodarske infrastrukture in vsebuje vse pomembne standardne GIS-funkcije, vendar je predvsem namenska rešitev, saj vsebuje tipske industrijske ali uporabniško dopolnjene podatkovne modele $^{3}$ za upravljanje infrastrukture s pripadajočimi napravami in objekti. Sistem temelji na AutoCAD Map 3D, Autodesk Infrastructure Map Server in Oracle Spatial bazi. Za uporabnike na MO je nadgrajen z dodatnimi spletnimi programskimi moduli ${ }^{4}$, narejenimi po uporabniških zahtevah in naročenimi pri zunanjem izvajalcu, kar je opisano v 7. poglavju. Vse to omogoča uporabo prostorskega podatka v celotnem življenjskem ciklu, od gradnje objektov, vodov in naprav, vzdrževanja, upravljanja, dograjevanja do ukinitve in zamenjave. Topobase je hkrati GIS in poslovni sistem v enem uporabniškem vmesniku, kar je njegova bistvena prednost.

Topobase v osnovnem paketu vsebuje industrijske podatkovne modele za več področij infrastrukture. To so tako imenovane vertikale, na primer vodovod, komunala, plin, elektrika, kot začetni podatkovni modeli z možnostjo prilagoditev, kreiramo lahko tudi svoje modele. Vsebuje prostorske informacije z atributnimi podatki o sklopih in elementih, na primer črpalke, merilni elementi, ventili itn., vsebuje predvidene šifrante, omogoča povezave med geometrijo objektov (v nadaljevanju topologija) in vnaprej pripravljene analitične postopke (www.autodesk.com, 2014).

\footnotetext{
Podatkovni model je abstraktna, vendar lahko razumljiva predstavitev potrebnih podatkov celotne organizacije oziroma njenega dela z vidika potrebnih podatkov.

${ }^{4}$ Programski moduli, nameščeni na strežniku kot nadgradnja osnovnega programa.
} 
Primeri dobre prakse so implementacije Topobase v tujini. Uporablja se na primer na mednarodnem letališču v Pragi, v elektrodistribucijskem podjetju Romande Energie ter v Industrielle Werke Basel - IWB (distributer za elektriko, plin, vodo, daljinsko ogrevanje, telekomunikacije) v Švici, v komunalnem podjetju Stadtwerke Augsburg in v podjetju Henkel Düsseldorf v Nemčiji, v madžarski geodetski upravi v Budimpešti, v več mestnih upravah na Švedskem ter v Las Vegas Valley Water District - LVVWD v ZDA (www.topobase.si, 2013).

Velika prednost je njegovo jedro, zmogljivo in razširjeno GIS-osnovno orodje AutoCAD Map 3D, ki med drugim omogoča odpiranje načrtov iz projektne dokumentacije $\mathrm{v}$ formatu $\mathrm{DWG}^{5}$ in s tem neposreden zajem geometrije in atributnih podatkov iz DWG-datotek. Povezavo na zunanje podatke (baze ali datoteke) omogoča tehnologija FDO Data Access Technology, ki izvira iz sodelovanja med Autodeskom in Open Source Geospatial Foundation ${ }^{\mathrm{TM}}$ OSGeo $^{\mathrm{TM}}$. (Slika ${ }^{6}$, str. 99)

Arhitektura sistema je grajena na podatkovni bazi Oracle z modulom Oracle Spatial (11gR2), strežniku in spletnih odjemalcih. Funkcionalnost prostorskega poizvedovanja in druge funkcionalnosti geoDBMS so del Oracle Spatial (Gregor, 2009). (Slika 2, str. 99)

$\mathrm{V}$ bazo se shranjujejo vsi prostorski in neprostorski podatki ter vsa pravila pri delu z bazo. Do baze dostopajo vse vsebinsko-skrbniške rešitve (Topobase Client, Topobase Administrator) ${ }^{7}$ ter vse spletne rešitve (pregledovalnik Infrastructure Map Server, nadgrajen z dodatnimi spletnimi programskimi moduli). Ker do podatkov vedno dostopamo v podatkovni bazi, so vsem uporabnikom, ne glede na vrsto dela in lokacijo dostopa, na voljo enaki in vedno ažurni grafični in atributni podatki. (Slika 3 , str. 100)

\section{PODLAGA ZA UVEDBO}

Letališče obratuje po predpisanih postopkih preventivnega vzdrževanja letaliških naprav, sistemov in infrastrukture. Postopke je treba načrtovati, preventivne in druge posege pa evidentirati tako, da je mogoče vzpostaviti natančen vpogled, kdaj in kako so bili izvedeni. Za ključne naprave je treba izdelati varnostno oceno ter določiti scenarij ukrepov in postopkov v primeru odpovedi delovanja posameznega sistema.

\footnotetext{
DWG-format datotečnega zapisa je uvedel Autodesk in je postal neformalni standard za CAD-programe. Skoraj vsi pomembni razvijalci komercialnih programov, vključno s tekmeci Autodeska, so se odločili podpreti format DWG za povezljivost podatkov z AutoCAD-om s programskimi knjižnicami, ki jih je izdelal neprofitni industrijski konzorcij Open Design Alliance.

${ }^{6}$ Programsko orodje je v angleškem jeziku, zato so tudi slike tega orodja v angleškem jeziku.

Vsebinske rešitve (Topobase Client) se uporabljajo za prikaz, vnos, napredno urejanje, prostorsko in statistično analizo ter poročanje v različnih evidencah (GURS ZKGJI, MOP, idr.). Skrbniške rešitve (Topobase Administrator) so za prilagoditve podatkovnega modela, nastavitve delovnih procesov, definicijo topoloških pravil (geometrična mreža, topologija površin, atributna topologija), administracijo uporabnikov in delovnih dokumentov, oblikovanje uporabniških form za končne uporabnike, nastavitev oblike, vrste in vsebine poročil in drugih izpisov ter arhiviranje (varnostne kopije, uvoz/izvoz instančnih podatkov, konfiguracije).
} 
Infrastrukturni objekti, naprave in sredstva morajo biti redno vzdrževani na predpisan način, njihovo stanje pa stalno nadzorovano (Uradni list RS 113/06 in 33/09, 2009).

Potreba po uvedbi sodobne računalniške aplikacije izhaja z več vidikov. Razdelimo jih lahko na normativne, to so podlage iz zakonov, predpisov in navodil, ter na izvedbene potrebe, to so predvsem uporabniške potrebe izvajalcev vzdrževanja za izvedbo nalog. To ne velja le za letališče, temveč za vse objekte in infrastrukturo nad določeno zahtevnostjo.

\subsection{Normativna podlaga za uvedbo}

Čeprav normativni vidik ni v strokovnem kontekstu tega prispevka, je treba navesti nekaj pravnih podlag glede vzdrževanja, ki zagotavljajo pogoje obratovanja, brez katerih letališče ne more obratovati.

Osnova je Zakon o graditvi objektov (ZGO), ki po končani gradnji zahteva projekt za vzdrževanje in obratovanje objekta ter tehnični pregled za uporabno dovoljenje (Uradni list RS 102/04, 2004). Po Zakonu o letalstvu so posebej predpisani tudi zagotavljanje kakovosti pri gradnji in vzdrževanju letališč, delovanje letaliških služb, zagotavljanje varnosti, pogoji za infrastrukturo in nadzor (Uradni list RS 113/06 in 33/09, 2009). Obstaja še približno 17 podzakonskih predpisov o letališčih, omenimo še vedno veljavni Pravilnik o vzdrževanju objektov, opreme in instalacij, pomembnih za varnost zračne plovbe na letališču (Uradni list SFRJ 9/84, 1984). Omeniti je treba tudi predpise, ki jih izdaja International Civil Aviation Organization - ICAO, na primer od leta 1984 nespremenjeni predpis za področje vzdrževanja letališč: Airport Service Manual Part 9 Airport Maintenance Practices (ICAO, 1984).

Vzdrževanje infrastrukture $\mathrm{v}$ upravljanju MO je do neke mere enakovredno vzdrževanju vseh podobnih objektov, vendar ima svoje posebnosti. Postopki vzdrževanja so zato izvedbeno predpisani z internimi akti. Na MO je to Navodilo za prostorsko načrtovanje in izvajanje investicij ter vzdrževanje infrastrukture Ministrstva za obrambo (Ministrstvo za obrambo, 2013), v katerem so opredeljeni redno in investicijsko vzdrževanje ter interventna dela, načrtovanje rednih in investicijsko-vzdrževalnih del, naročila del in pristojnosti glede vzdrževanja. V Slovenski vojski so izvedbeni akti standardni operativni postopki - SOP. Pripravljen je tudi SOP za področje vzdrževanja infrastrukture in objektov, v katerem so predpisana načrtovanje del z izvedenimi ustreznimi organizacijskimi in tehničnimi ukrepi, odgovorno in kakovostno vzdrževanje vojaške infrastrukture za stanje uporabne vrednosti infrastrukture na zahtevani ravni v času trajanja in $\mathrm{s}$ tem zagotavljanje pogojev za nemoteno delovanje enot in poveljstev v objektih SV (Slovenska vojska, GŠSV, 2011).

Posebej je treba poudariti, da je v tem SOP-u poleg zahtevane besedilne in podatkovne dokumentacije izrecno zahtevana georefencirana dokumentacija, torej shematski in situacijski načrti. Zahtevani so najmanj naslednji načrti: tehnične skice in načrti, načrti objektov, naprav in instalacij, vodenje kataloga objektov vojašnice, ki obsega 
načrte vojašnice in dislociranih objektov ter vseh instalacij (električne, vodovodne, toplovodne, kanalizacija).

Zaključimo lahko, da predpisi neposredno ne zahtevajo informacijske podpore, potreba izhaja posredno zaradi predpisanih ostrih pogojev.

\subsection{Izvedbena podlaga za uvedbo}

Tudi izvedbena podlaga, to so predvsem uporabniške potrebe, na videz ni neposredno povezana z geoprostorskimi tehnologijami, vendar iz primerov dobre prakse vidimo, da je geoprostorska podpora potrebam izvajalcev vzdrževanja nujna.

Geoprostorska podpora rešuje in poenostavlja številne postopke. Lahko naštejemo nekaj osnovnih primerov, $\mathrm{v}$ katerih je ta podpora nujna in bi bile naloge brez nje skoraj neizvedljive:

a) energetska, komunikacijska in komunalna infrastruktura na terenu in v zgradbah, v katero brez zanesljivih situacijskih načrtov, iz katerih pridobimo točno lokacijo, ne moremo posegati;

b) podrobni tlorisni načrti prostorov v objektih, ki omogočajo hitro in zanesljivo načrtovanje obnavljanja ali čiščenja tal, osteklitve in sten;

c) določitev vseh prizadetih odjemalcev, če zapremo neki ventil ali če izklopimo neko transformatorsko postajo;

d) posodobitev inštalacij, napeljav, tehnoloških naprav in opreme zaradi napredka tehnike ali dotrajanosti;

e) analiza poti, razdalj in časov za intervencijska vozila;

f) določitev površin za pluženje snega ali košnjo trave;

g) prostorsko načrtovanje, projektiranje, gradnja in rekonstrukcije.

Pri vzdrževanju infrastrukture in objektov je treba poudariti prve štiri zgornje primere. Zanje velja, da nam poleg osnovnega kartografskega prikaza s poljubno kombinacijo vidnosti slojev na karti GIS-tehnologija omogoča višjo raven uporabe, to so prostorske poizvedbe, poizvedbe z atributnimi merili, analize in topologija. Topologija so tukaj logične povezave med objekti, predvsem med elementi instalacij (primer c). (Slika 4, str. 100 in slika 5, str. 101)

Primer g) je treba podrobneje opisati glede prostorskega načrtovanja, pri katerem moramo omeniti območja varovanja oziroma območja omejene in nadzorovane rabe nekaterih objektov, kot so letališča, strelišča, skladišča in območja za uničevanje minskoeksplozivnih sredstev. Za letališča so po letalskih predpisih opredeljena območja izključne rabe, območja možne izključne rabe ter območja omejene in nadzorovane rabe (Uradni list RS 113/06 in 33/09, 2009). Vsi posegi v prostor morajo upoštevati predpise, ki na teh območjih veljajo. Podobno je pri skladiščih nevarnih ali eksplozivnih snovi in drugih objektih s širšim vplivom, kot so na primer strelišča. 
Pri projektiranjih za gradnjo in rekonstrukcije je vedno treba že na začetku projektiranja imeti stanje terena, objektov, katastra, inštalacij, vplivnih območij ipd. iz zanesljivega vira, ki je ažuren in pomeni realno stanje.

Iz naštetih primerov lahko vidimo, da je geoprostorska podpora uporabniškim potrebam izvajalcev vzdrževanja potrebna in utemeljena. Tudi primeri dobre prakse geoprostorske podpore dokazujejo nujnost informacijske geoprostorske podpore za vzdrževanje zahtevnejših objektov.

\section{NAMEN IN CILJI SISTEMA}

Osnovni namen je postavitev GIS in poslovnega sistema za podporo obratovanja in vzdrževanja infrastrukture letališča, ki omogoča spremljanje življenjskega cikla različnih sistemov na letališču od postavitve do obratovanja in vzdrževanja ter prikaz delovanja njihovih funkcij in obvladovanje velikega obsega podatkov za ožje in širše območje letališča. Sistem mora zagotavljati:

- Funkcionalnosti skladno s potrebami končnega uporabnika, ki so določene $\mathrm{z}$ analizo uporabniških potreb in internimi akti.

- Vnos, obdelavo in prikaz geoprostorskega gradiva:prostorski podatki iz situacijskih načrtov objektov in infrastrukture, pridobljeni z migracijo projektnih načrtov $\mathrm{PID}^{8}$, po navodilu za migracijo, čiščenje ter preverjanje podatkov in zagotavljanja ustrezne kakovosti podatkov (glej: 6 Vnos geoprostorskih in atributnih podatkov), drugi geodetski, topografski, letalski, hidrografski, kartografski in slikovni podatki ali informacije v kateri koli obliki, ki so georeferencirani v prostoru.

- Vnos in pregledovanje povezane tehnične dokumentacije v elektronski obliki, in sicer skeniranih dokumentov ali izvorno digitalnih dokumentov: nabavne podatke, tehnične podatke, logične sheme instalacij in postrojenj, navodila za vgradnjo in delovanje, navodila za uporabo, vzdrževanje in razgradnjo, kataloge rezervnih delov, garancije, certifikate, poročila opravljenih meritev, načrte plašča jaškov, načrte evakuacije, varnostni in požarni red, fotografije fizičnega videza naprav itn.

- Možnost povezovanja na druge baze in sisteme, na primer katastre (parcele, stavbe, $\mathrm{RPE}^{9}$ ), rastre (topografske karte, $\mathrm{DOF}^{10}$ ), poslovne sisteme, nadzorne in upravljalne sisteme letališča (SCADA - Supervisory Control And Data Acquisition - za energetiko, osvetlitev vzletno-pristajalne steze, CNS-centralni nadzorni sistem, varovanje).

- Razdelitev podatkov na geodetske podlage, situacijske načrte objektov in instalacij, atributne podatke ter digitalne dokumente, povezane z objekti.

\footnotetext{
8 PID - Projekt izvedenih del.

9 RPE-Register prostorskih enot.

${ }^{10}$ DOF - Digitalni ortofoto posnetki (tako satelitski kot iz drugih virov).
} 


\section{DEFINIRANJE ZAHTEV, GLAVNIH ZNAČILNOSTI IN IZBOR SISTEMA}

Osnovna zahteva je vzpostavitev računalniške podpore za uspešno in učinkovito obratovanje ter vzdrževanje celotnega kompleksa letališča, kar bo eden najpomembnejših gradnikov letališkega informacijskega sistema. Za določanje zahtev sta bili izvedeni analiza stanja in preučitev potreb uporabnika. Analiza stanja je bila izvedena pri bodočih uporabnikih in je obsegala analizo postopkov, dokumentov, kadrov in predpisov. Iz te analize izhajajo potrebe uporabnikov.

Glavne značilnosti sistema določajo analize postopkov, dokumentov, kadrov in predpisov. Ugotovljeno je, da zahtevanim značilnostim ustreza sistem, ki pokriva področje upravljanja gospodarske infrastrukture, vsebuje vse pomembne standardne GIS-funkcije, je namenska rešitev z značilnimi industrijskimi ali uporabniško dopolnjenimi podatkovnimi modeli $\mathrm{v}$ bazi podatkov in ima vse poslovne funkcije za potrebe uporabnikov. Tako je bila zasnovana arhitektura sistema, ki temelji na podatkovni bazi, v katero se shranjujejo vsi prostorski in neprostorski podatki, pravila pri delu z bazo in obseg funkcionalnosti sistema. Poslovne funkcije so bile natančno določene po opravljeni preučitvi potreb uporabnikov. Za izbor sistema so bila tako določena kakovostna merila. Pregledane so bile sedanje rešitve na trgu. Primerjalna analiza glede na potrebe končnega uporabnika je pokazala, da je Topobase primeren sistem za upravljanje prostorske baze podatkov v podporo upravljanju letališča, operativnim službam in vzdrževanju na letališču Cerklje. Proizvajalec je Autodesk, zato je zagotovljena podpora projektantskim načrtom, ki so izdelani s CAD-orodjem AutoCAD.

\section{PILOTNI PROJEKT}

Glede na zahtevnost in obseg sistema je bilo treba z razpisom poiskati zunanjega izvajalca, ki je dobavil strojno opremo (strežnik), licenčno programsko opremo, opravil vse podporne dejavnosti (namestitev, konfiguracijo, usposabljanje, podporo, vnos podatkov v bazo) in izdelal po zahtevah uporabnikov prilagojene programske nadgradnje (glej: 7 Nadgradnja osnovnega sistema z dodatnimi moduli).

Izbrani izvajalec je začel pilotni projekt. Format pilotnega projekta je bil v izdelavi prototipne aplikacije $\mathrm{z}$ osnovno funkcionalnostjo Topobase in $\mathrm{z}$ namenom identifikacije postopkov uvoza in vnašanja $\mathrm{v}$ Topobase. Integrirane so bile javne infrastrukturne baze in vnesena izbrana projektna dokumentacija infrastrukture, objektov ter tehnoloških naprav. Med preverjanjem ustreznosti orodja je projektna skupina pripravila okrnjeno zbirko podatkov, na kateri je lahko testirala funkcionalnost. Izvedeno je bilo:

- povezava med CAD-načrti projektantov infrastrukture in GIS,

- testiranje sledenja po vodovodnem omrežju za določanje napak,

- prikaz podatkov analize hrupa v okolici letališča,

- 3D-prikaz reliefa in omejitvenih ravnin letališča,

- tečaj in štiri delavnice. 
Pilotni projekt je potekal leta 2009, konec leta 2010 je bil končan prvi del vnosa podatkov, leta 2011 drugi del vnosa podatkov ter razvoj dodatne funkcionalnosti za podporo vzdrževanja objektov in infrastrukture. Izvajalec trenutno še razvija dodatne funkcionalnosti, osnova je podroben načrt razvoja.

\section{VNOS GEOPROSTORSKIH IN ATRIBUTNIH PODATKOV}

Vsak vnos $\mathrm{v}$ bazo Topobase poteka po enotnem postopku migracije podatkov. Datoteka DWG je poglavitni vir podatkov za vnos v aplikacijo Topobase, zato je treba pri risanju načrtov za PID v AutoCAD-u upoštevati ustrezna pravila risanja. DWGdatoteka mora izpolnjevati dva pogoja: da prikazuje resnično stanje izvedenih del, preverjenih na terenu, in da izpolnjuje pravila risanja oziroma standarde za prenos podatkov v Topobase. Pravila risanja obsegajo osnovna pravila risanja, koordinatni sistem in merilo, pravila za organiziranost slojev, pravila za točkovne, linijske in površinske elemente ter šrafure in pravila za notacije oziroma besedilne oznake.

Zunanjim izvajalcem projektne dokumentacije je bilo treba postaviti standarde, da bi se zmanjšala obdelava podatkov pred uvozom v podatkovne modele Topobase. Uvoz podatkov je namreč migracija v smislu pretoka podatkov iz enega sistema (datotečni) v drug sistem (objektno-relacijski). Pripravljeno je bilo navodilo za projektante oziroma izdelovalce projektne dokumentacije PID, v dokumentu Minimalne zahteve za pripravo AutoCAD DWG-načrtov za vnos v Topobase. Tudi v pogodbi z izvajalcem gradbeno-obrtniških in instalacijskih del, ki mora na koncu del predati projekt izvedenih del, je določilo, ki zavezuje k upoštevanju tega navodila.

Za lažjo izvedbo pravil za notacije oziroma besedilne oznake je bilo izdelano programsko orodje v programskem jeziku AutoLISP, ki v okolju AutoCAD avtomatizira pretvorbo besedilnih notacij oziroma oznak točkovnih elementov ${ }^{11}$ (vnesenih kot besedilo) v nov tip oznak, ki vsebujejo točno lokacijo točkovnega elementa $\mathrm{v}$ koordinatnem sistemu. To velja za situacijske, lokacijske, tlorisne načrte in podobne risbe, ki imajo elemente na pravilnih lokacijah oziroma pravilnih koordinatah, ne velja pa za shematske risbe, kot so vezalne sheme, sheme strojnih instalacij in druge sheme. (Slika 5, str. 101 in slika 7, str. 102)

Podatki za vnos so dveh poglavitnih zvrsti: geometrijski in atributni. Geometrijski podatki so predvsem v datotekah DWG in $\mathrm{SHP}^{12}$. Atributni so bolj porazdeljeni in zahtevajo več organizacije za pridobitev, ker so večinoma v tekstualni dokumentaciji. Pomemben je izbor ustreznih podatkov za vnos v bazo v predpripravljena podatkovna polja. (Slika 8, str. 102)

Dokumentacija je za uporabnike potrebna tudi v izvorni obliki. To so predvsem skenirani ali izvorno digitalni dokumenti, zato je kot dodana vrednost nad podatki

"I Točkovni elementi so elementi v omrežju, npr. jaški, hidranti in ventili.

${ }_{12}$ Datoteka SHP je standard za izmenjavo prostorskih podatkov med uporabniki geografskih informacijskih sistemov (GIS). 
dokumentni sistem z referenco v prostoru, ki omogoča, da vsakemu geolociranemu objektu dodamo poljubno število e-dokumentov. Uporabniki lahko sami dodajajo in odvzemajo dokumente, vnašajo opombe, odpirajo pripete dokumente in jih natisnejo. To predstavlja centralen ažuren katalog dokumentacije za službo vzdrževanja, pa tudi drugih služb (dežurstva, varovanje, gasilci itn.), ki potrebujejo osnovne podatke o vojašnici, objektih in infrastrukturi, kot so tehnični podatki, navodila za vgradnjo, uporabo, vzdrževanje, nabavni podatki, vezalne sheme, sheme strojnih instalacij, katalogi rezervnih delov, garancije, certifikati, poročila o prevzemih, pregledih, meritvah itn. (Slika 9, str. 103)

Vnesti je mogoče tudi fotografije, na primer za lažje določevanje naprav, ki so lahko vnesene v Topobase iz fotoaparata ali mobilnega telefona. (Slika 10, str. 103)

V grafično okno lahko uvozimo geodetske podloge (npr. ortofoto posnetke, kataster stavb, kataster parcel) na dodatne sloje, prek FDO Data Access Technology. (Slika 11, str. 104)

\section{NADGRADNJA OSNOVNEGA SISTEMA Z DODATNIMI MODULI}

Temeljna zahteva je bila vzpostavitev računalniške podpore za uspešno in učinkovito obratovanje ter vzdrževanje celotnega kompleksa letališča. Osnova sta bili analiza stanja (postopkov, dokumentov, kadrov, predpisov) in preučitev potreb uporabnika ter normativne podlage. Pripravljen je bil tako imenovani Business Blueprint oziroma opis poslovnih procesov, ki v glavnih točkah vsebuje:

- definicijo obrazca ZPI - Zahtevek za popravilo infrastrukture. Obrazec je osnova za postopke in evidence vzdrževanja;

- proces tekočega vzdrževanja infrastrukture - TVI. Razdeljen je na faze ter na pristojnosti izvrševanja in pravice izpolnjevanja ter zaključevanja ZPI-obrazcev. Uporabniki imajo po prijavi v sistem dodeljeno ustrezno vlogo, s katero so povezane pravice uporabe;

- dodajanje dokumentov k predmetom vzdrževanja, evidenca dokumentov;

- iskanje po ZPI ali po lastnostih naprav;

- prikaz statusa naprav;

- koledar vzdrževanja za načrtovanje aktivnosti $\mathrm{z}$ evidenco prednostnih in dolgoročnih vzdrževalnih del, intervencijskih popravil in garancijskih del;

- evidenco vseh dogodkov (vzdrževanje, zamenjave, intervencije itn.);

- poročila: po skrbniku, objektu, datumih, izvajalcu - lastni ali zunanji;

- točen lokacijski prikaz na situaciji oziroma zemljevidu letališča za vse objekte, inštalacije in naprave;

- poizvedbe po lokaciji, objektu, vodu, napravi oziroma sklopu naprav ali po izbranih merilih;

- arhiv normativnih dokumentov s področja vzdrževanja (direktive, ukazi, SOP)

(Skvarča, 2013). 
Po opravljenih analizah in oblikovanem opisu poslovnih procesov v Business Blueprintu je bila zaradi prepričanja, da se pri vsakodnevnem delu uspešno uporabljajo le računalniška orodja, ki so prilagojena uporabniškim potrebam, ugotovljena potreba po prilagojeni nadgradnji. Priprava nadgradnje je bila naročena pri zunanjem izvajalcu na podlagi Business Blueprinta z zahtevami:

- izdelava podrobnejših specifikacij nadgradnje in protokola testiranja,

- izdelava delujočega prototipa nadgradnje,

- testiranje prototipa,

- dopolnitev prototipa do produkcijske različice,

- izdelava uporabniških navodil v tiskani in elektronski obliki znotraj aplikacije,

- izobraževanje uporabnikov.

\section{REŠEVANJE TEŽAV PRI IZVEDBI}

V procesu implementacije so bile zaznane težave:

1. Podaljšanje testnega obdobja zaradi velike zasedenosti testnih uporabnikov s službenimi nalogami. Ta težava skoraj ni vplivala na doseženo raven kakovosti sistema, bolj na zakasnjen začetek testne uporabe na praktičnih nalogah.

2. Veliko število predlaganih dopolnitev med testiranjem, kar je zahtevalo utemeljitev in izbor predlogov, ki so primerni za apliciranje in posledično dodatno usklajevanje z drugimi uporabniki in zunanjim izvajalcem. Vendar je velika količina teh predlogov imela pozitiven učinek na povečanje praktične uporabnosti.

3. Zagotavljanje dodatnih strežnikov za povečanje zanesljivosti delovanja in ločitev produkcijskega strežnika ter strežnika za razvojno-testno okolje.

4. Napake $\mathrm{v}$ programu, ki so se pokazale pri testni uporabi, vendar pa niso povzročile večjih zastojev in jih je izvajalec sproti odpravljal, kar je bil seveda tudi poglavitni cilj testiranja, da se odpravijo funkcionalne, logične in strukturne napake.

\section{DOSEDANJI REZULTATI PRI PRAKTIČNI UPORABI}

Dosedanji rezultati so referencirani v generiranih poročilih iz aplikacije, v predhodno načrtovanih funkcionalnostih ter $\mathrm{v}$ mnenjih uporabnikov po trimesečni uporabi pri rednih nalogah. Opisano je stanje rezultatov marca 2015.

Po podatkih iz samodejno generiranih poročil v Topobase je bilo od 1. januarja 2015 kreiranih 57 zahtevkov za popravilo infrastrukture (periodično, zakonsko, interventno popravilo), od tega je 22 zahtevkov uspešno zaključenih. Tako je na podlagi prvega tromesečja ocena za vse leto približno 240 zahtevkov.

Glede na predvideno funkcionalnost je ocenjeno, da je dosežena 95-odstotna zahtevana funkcionalnost aplikacije in da bo pogodbena funkcionalnost izpolnjena v nekaj tednih. Dodatno je predviden nadaljnji razvoj, in sicer dodatne izboljšave, ki 
jih predlagajo uporabniki. Nadaljnji razvoj je predviden kot mogoča nova pogodba z zunanjim izvajalcem.

Mnenja uporabnikov po trimesečni uporabi pri rednih nalogah:

»Zadovoljni smo z uporabo Topobase. Večino nalog izvajamo prek Topobase. Topobase je v sedanji stopnji razvoja polno uporaben. Pri opravljanju nalog vzdrževanja smo zaznali hitrejše odzivne čase, hitrejše posredovanje soudeleženim, boljše načrtovanje, evidence in izdelavo poročil, manj je zamudne »papirologije«. Potrebne so še manjše izboljšave.«

Iz teh rezultatov lahko zaključimo, da sta dokazani uporabnost in učinkovitost aplikacije. V primerjavi s prejšnjimi postopki z orodji Word, Excel, tiskanjem obrazcev, kopiranjem podatkov, papirnimi arhivi ipd. je dokazan velik napredek, očitno je zadovoljstvo uporabnikov, uspešnost testne uporabe pri rednih nalogah je vidna iz števila izvedenih nalog.

\section{POVEZOVANJE S TRENUTNIMI POSLOVNIMI SISTEMI NA MO}

Sistem Topobase je bil vključen tudi v projekt integracije baz prostorskih podatkov za upravljanje prostora in gospodarjenje $\mathrm{z}$ nepremičninami na $\mathrm{MO}$ in $\mathrm{v}$ projekt preoblikovanja centralne baze prostorskih podatkov ter vzpostavitve enotne vstopne točke za vodenje različnih evidenc nepremičnin v upravljanju in interesu MO. S slednjim projektom se rešuje težava več podatkovnih baz na MO in v SV s področja upravljanja prostora, kot so na primer nepremičnine v uporabi MO, evidenca obrambnih območij, popis objektov v uporabi MO, evidenca stanovanj v uporabi MO in računovodski podatki o nepremičninah. Po končanju projekta bodo omogočeni poizvedovanje, priprava poročil, izdelava analiz oziroma strateških vpogledov, minimalizacija redundance podatkov in vmesnega preverjanja ter samostojen vpogled, dostop $\mathrm{z}$ ene informacijske točke in poenostavljeno pridobivanje mnenj notranjih organizacijskih enot MO pri posegih v prostor ter investicijskih posegih.

Sklep Sistem Topobase v produkcijski uporabi omogoča obvladovanje velikega obsega podatkov za ožje in širše območje letališča. Z njim na podatkovni ravni združujemo dokumentacijo, postopke vzdrževanja in obratovanja Letališča Cerklje ob Krki, situacijske načrte infrastrukture ter podloge iz GURS-a v naslednje osnovne tipe podatkov:

1. situacijski načrti objektov in instalacij,

2. atributni podatki,

3. digitalni dokumenti, povezani z objekti, kot so nabavni podatki, tehnični podatki, logične sheme instalacij in postrojenj, navodila za vgradnjo in delovanje, navodila za uporabo, vzdrževanje, razgradnjo, katalogi rezervnih delov, garancije, certifikati, poročila opravljenih meritev, načrti plaščev jaškov, načrti evakuacije, varnostni in požarni red,

4. geodetske podlage. 
Na funkcionalni ravni vsebuje funkcionalnosti za operativno vzdrževanje letališča: vzdrževanje infrastrukture, časovno načrtovanje vzdrževanja, evidenco izvedenih načrtovanih, intervencijskih in garancijskih posegov in popravil, poročila in analize opravljenih del, izpise obrazcev ter celotno zmogljivost GIS-sistema, podprtega s podatkovno bazo.

Sistem Topobase bo v primeru uspešnega zaključka testiranja, implementacije in uvedbe v operativno uporabo na Letališču Cerklje ob Krki služil kot referenca in bo lahko uporabljen tudi širše, za druge objekte v upravljanju MO. Univerzalna uporabnost rešitve je zagotovljena zaradi upoštevanja normativnih podlag, kot so pravilniki za postopke vzdrževanja infrastrukture in objektov, ter upoštevanja uporabniških potreb. V okviru nadaljnjega razvoja se že načrtuje razširitev funkcionalnosti za vzdrževanje celotne infrastrukture in objektov v upravljanju MO.

\section{Literatura}

1. Autodesk, Inc., 2010. Best Practices for Managing Geospatial Data. San Rafael: Autodesk, Inc., http://images.autodesk.com/adsk/files/best_practices_for_managing_ geospatial datal.pdf, 16. 12. 2014.

2. Gregor, Dejan, 2009. Arhitektura sistema Autodesk Topobase. Ljubljana: CGS plus.

3. Uradni list $R S 113 / 06$ in 33/09, 2009. Zakon o letalstvu (ZLet). Ljubljana: Uradni list Republike Slovenije.

4. Uradni list RS 102/04, 2004. Zakon o graditvi objektov (ZGO-1). Ljubljana: Uradni list Republike Slovenije.

5. ICAO, 1984. Airport Service Manual Part 9 Airport Maintenance Practices. Montreal: International Civil Aviation Organization.

6. Uradni list SFRJ 9/84, 1984. Pravilnik o vzdrževanju objektov, opreme in instalacij, pomembnih za varnost zračne plovbe na letališču. Beograd: Uradni list SFRJ.

7. Ministrstvo za obrambo, 2013. Navodilo za prostorsko načrtovanje in izvajanje investicij ter vzdrževanje infrastrukture MO. Ljubljana: Ministrstvo za obrambo.

8. Slovenska vojska GŠSV, 2011. SOP št. 1416 Načrtovanje, izvajanje in poročanje za tekoče vzdrževanje vojaške infrastrukture.

9. CGS plus d.o.o., 2013. Primeri najboljše prakse. http://www.topobase.si/, 9. 8. 2013.

10. Autodesk, Inc., 2014. Publish and share GIS maps. San Rafael: Autodesk, Inc., http:// www.autodesk.com/, 24. 3. 2014.

11. Skvarča, Andrej, 2013. Business Blueprint specifikacije za nadgradnjo Topobase. Ljubljana: Ministrstvo za obrambo. 
Slika 1:

Vmesnik

za končne

uporabnike

(menuji in

grafično

okno) znotraj

brskalnika

Figure 1:

Final user

interface (menus

and graphic

window) within

a browser
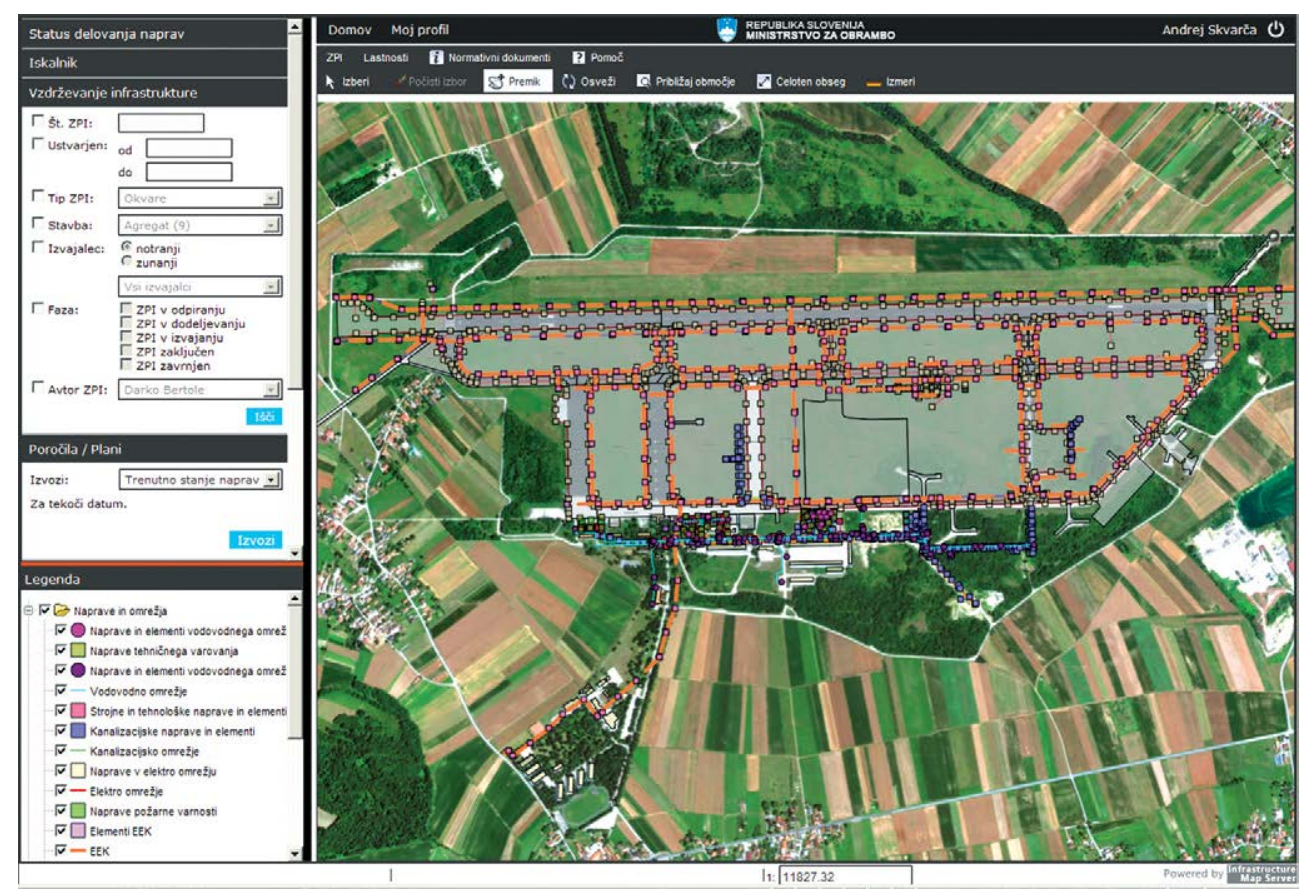

Slika 2:

Arhitektura

sistema

Topobase

Figure 2:

Topobase

system

architecture
Business Systems Autodesk Topobase

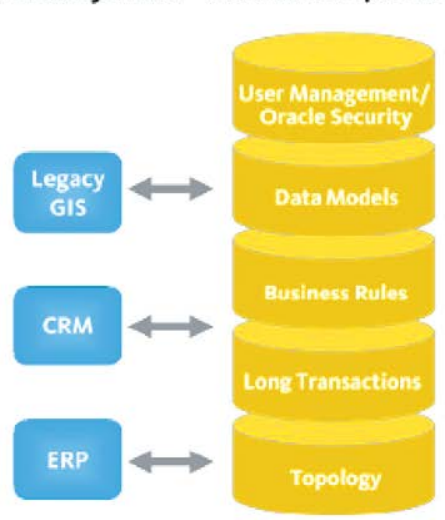

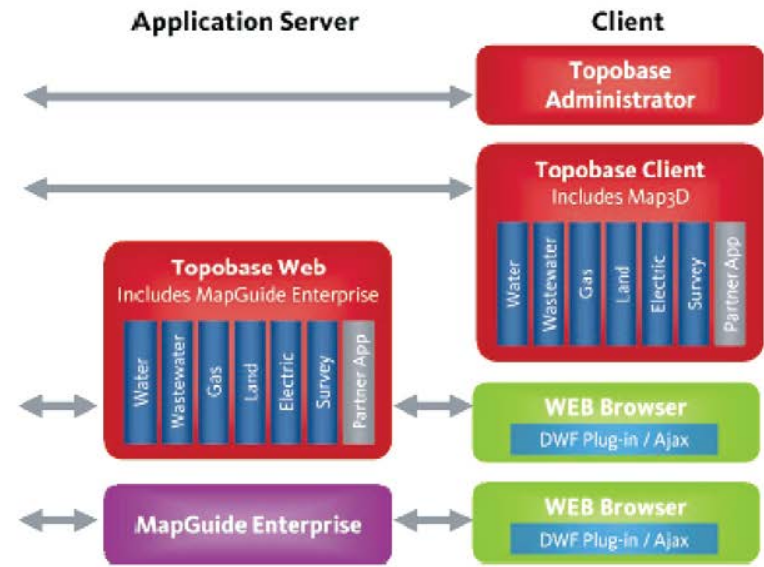


Slika 3:

Shranjevanje

podatkov

$\checkmark$ bazi in

različni dostopi

uporabnikov

do njih

Figure 3: Saving data in a database and various forms of user access

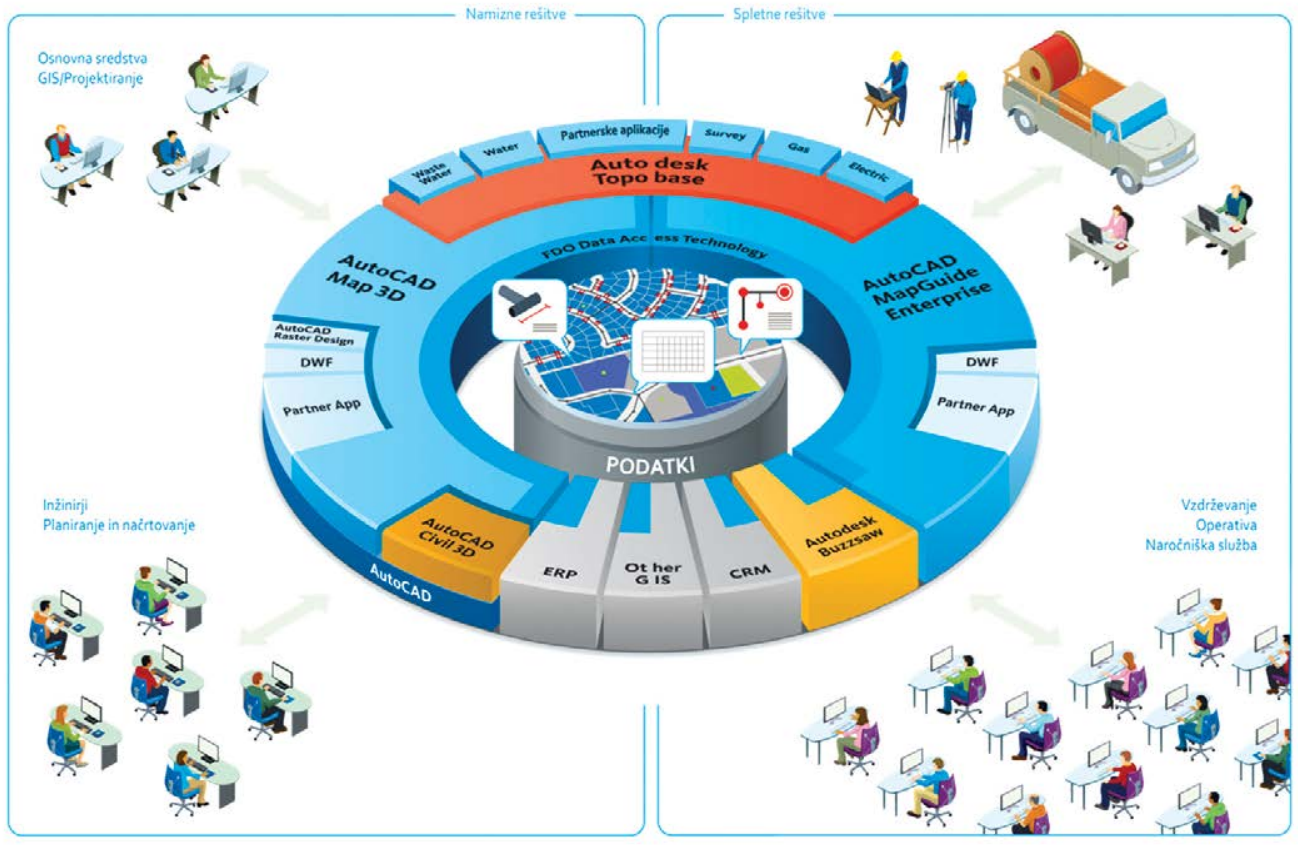

Slika 4: Načrtovanje obnavljanja ali

čiščenja tal, osteklitve in sten

Figure 4: Planning of renovations or the cleaning of floors, glass surfaces and walls

\section{Columns:}

$\checkmark$ Stavba: (STAVBA)

$\checkmark$ Id prostora: (ID_PROSTORA)

$\square$ Površina tal (AREA)

$\checkmark$ Materila tlakov: (MATERIAL_TLAKOV)

$\checkmark$ Površina sten: (POVRSINA_STEN)

Etažna višina: (ETAZNA_VISINA)

$\square$ Površina stekel: (POVRSINA_STEKEL)

$\checkmark$ Feature ID: (FID)
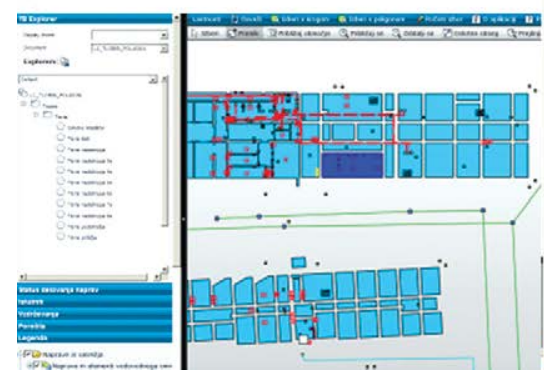

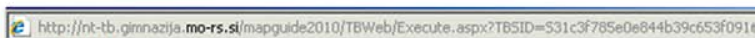
Form Table

\begin{tabular}{|c|c|c|}
\hline Feature $\mathbf{D}$ : & & 793 \\
\hline Stavbs: & Letairski stolo & \\
\hline Id prostora: & & \\
\hline Povrśina tal & & 49,06000000 \\
\hline Materia tlakov: & PVC & \\
\hline Povrsina sten: & & 102,00 \\
\hline Etažna višina: & & 3.00 \\
\hline Površina steket & & 0,00 \\
\hline
\end{tabular}

Record 1 of 1 (Filter active)

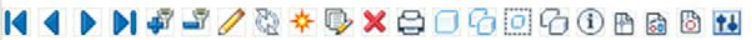


Slika 5:

Primera mrežne

topologije (npr.

cevovodov)

in topologije

površin (npr.

tloris letališča)

(Vir: http://www.

topobase.si/,

9. 8. 2013)

Figure 5:

Examples

of network

topology (e.g.

pipe-work) and

surface topology

(e.g. ground

plan of an

airport) Source:

http://www.

topobase.si/, 9

August 2013
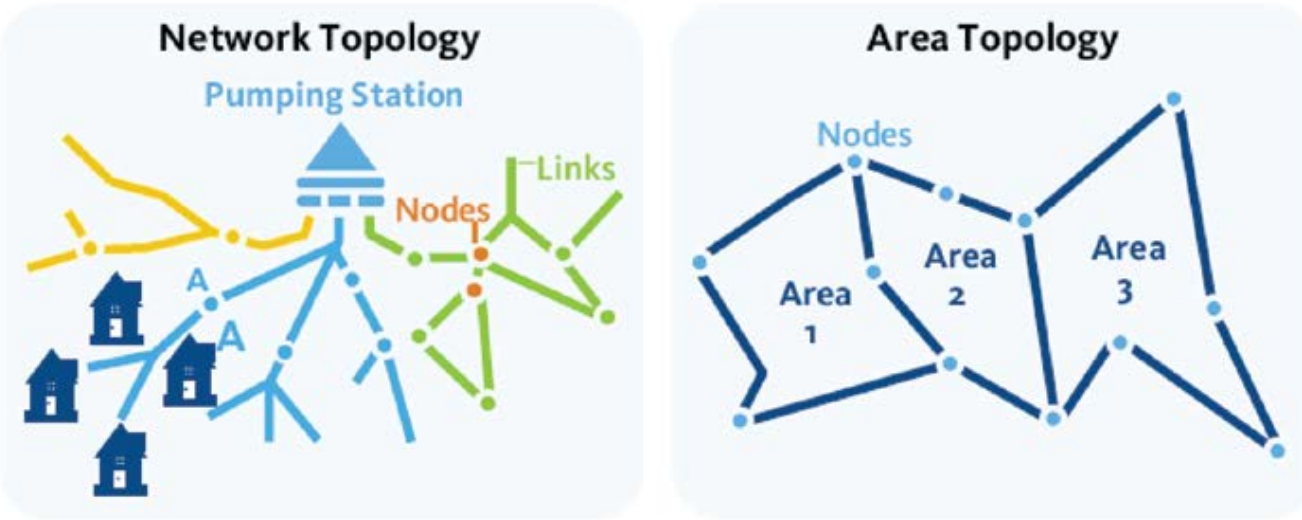

Slika 6: Situacijski načrt elektro kabelske kanalizacije

Figure 6: Situational plan of electric cable duct

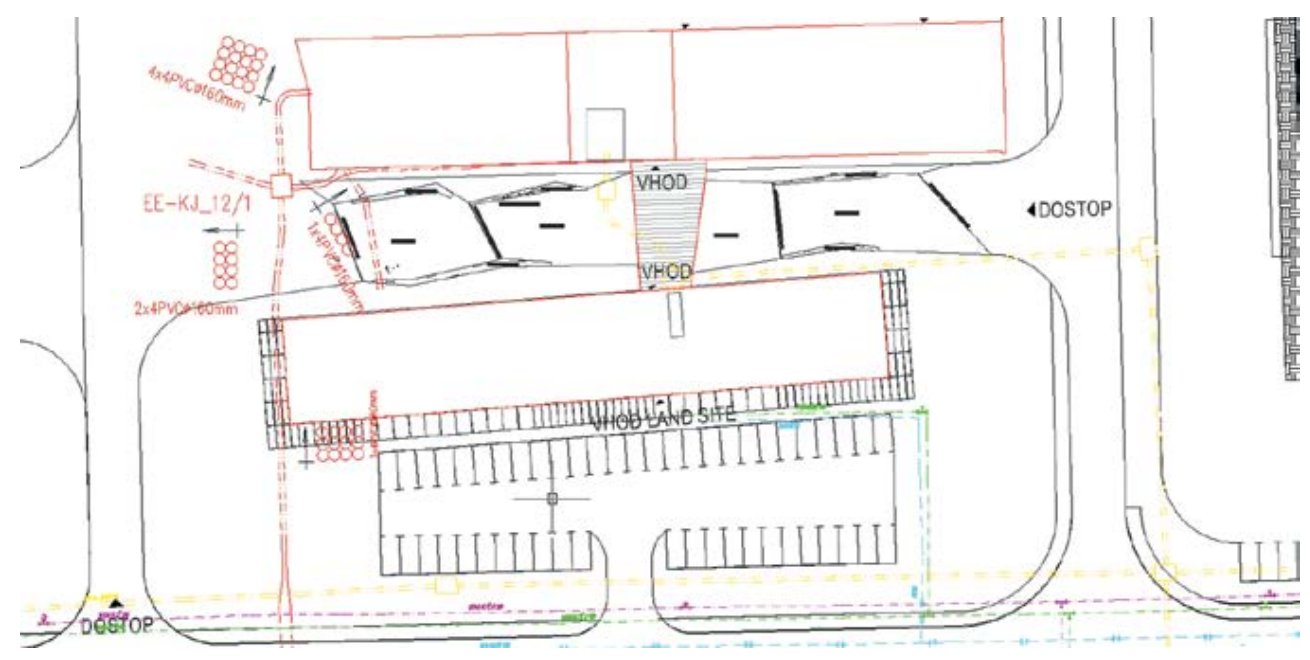


Slika 7:

Primer

nejasnega

poimenovanja

slojev v DWG-

datoteki

zaradi kratic,

manjkajočih

besed in opisov

Figure 7:

Example of

ambiguous

layer names in

a DWG file due

to abbreviations,

missing words

and descriptions

\begin{tabular}{|c|c|c|c|c|c|c|c|c|c|c|c|}
\hline 至 & \multicolumn{4}{|l|}{ Current layer: 00-tloris } & & & & & & \multicolumn{2}{|c|}{$\begin{array}{r}\text { Pearch for layer } \\
\qquad 89\end{array}$} \\
\hline & 烦 Filters & 5. & Name & , & \begin{tabular}{|l|l} 
O.. Fre... \\
\end{tabular} & L.... Color & Linetype & | Lineweight & | Plot Style & | Plot & New $A$ \\
\hline む & 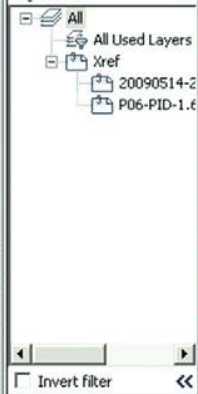 & . & 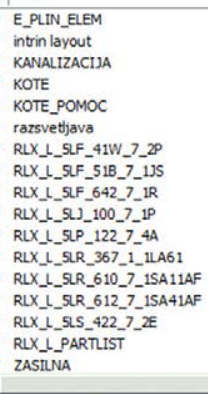 & & 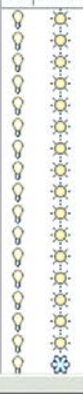 & 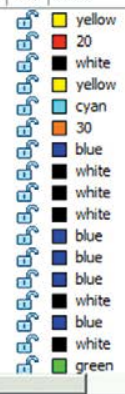 & 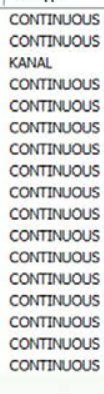 & 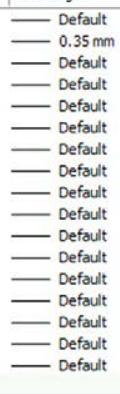 & $\begin{array}{l}\text { Color_2 } 2 \\
\text { Color_20 } \\
\text { Color_7 } \\
\text { Color_2 } \\
\text { Color_4 } \\
\text { Color_30 } \\
\text { Color_5 } \\
\text { Color_7 } \\
\text { Color_7 } \\
\text { Color_7 } \\
\text { Color_5 } \\
\text { Color_5 } \\
\text { Color_5 } \\
\text { Color_7 } \\
\text { Color_5 } \\
\text { Color_7 } \\
\text { Color_3 }\end{array}$ & 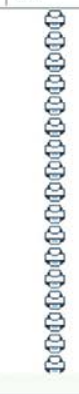 & $\bar{F}$ \\
\hline
\end{tabular}

Slika 8:

Atributni

podatki naprave

Figure 8:

Attribute data

of a device

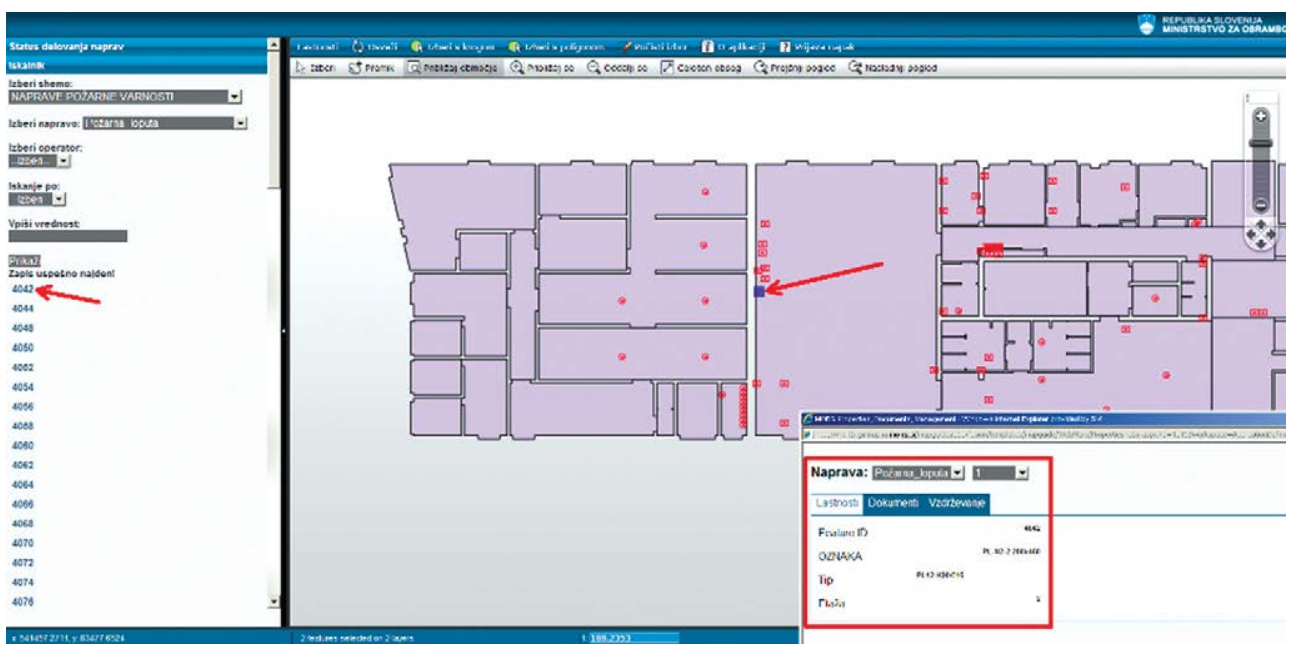


Slika 9:

E-dokument

$\mathrm{z}$ referenco

$\checkmark$ prostoru,

kot skeniran

digitalni

dokument

Figure 9:

E-document

with area

reference as a

scanned digital

document

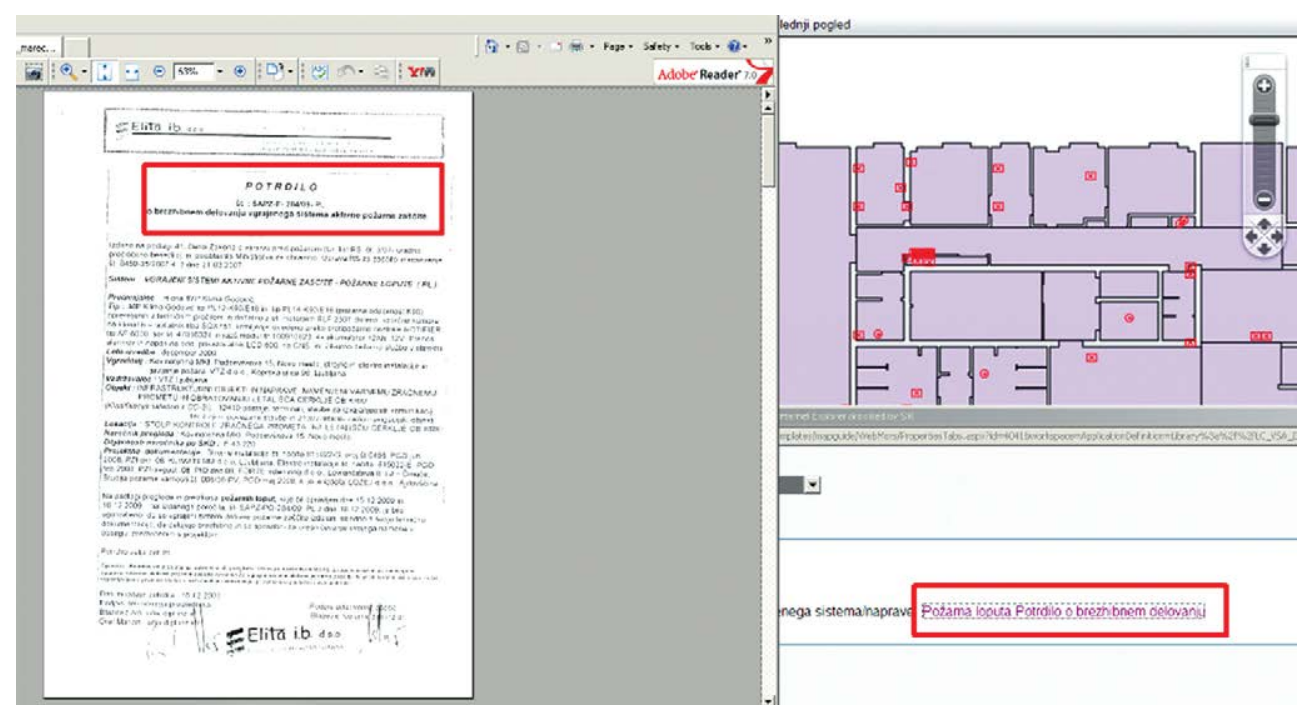

Slika 10:

Fotografije naprav, dodane kot e-dokument

Figure 10: Photographs of devices, attached as an e-document

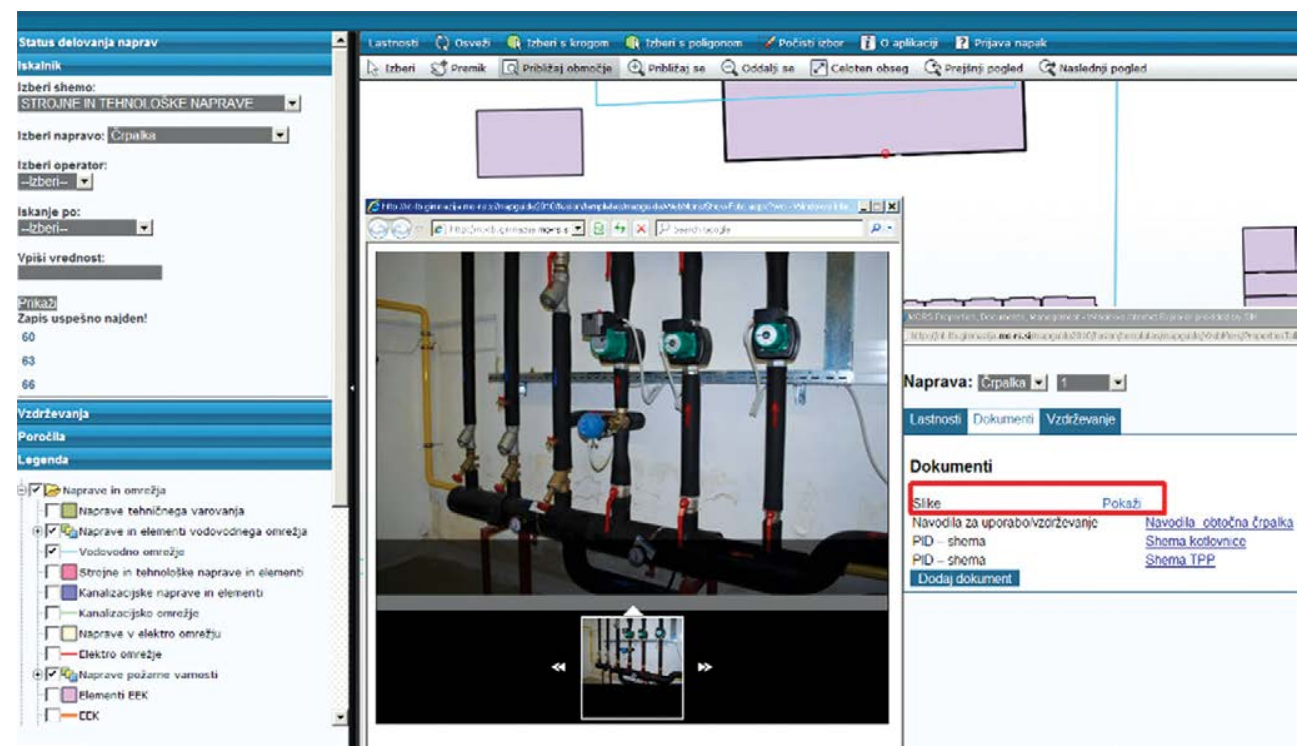


Slika 11:

Migracija geodetskih podlog in infrastrukture letališča

Figure 11: Migration of geodetic linings and airport infrastructure

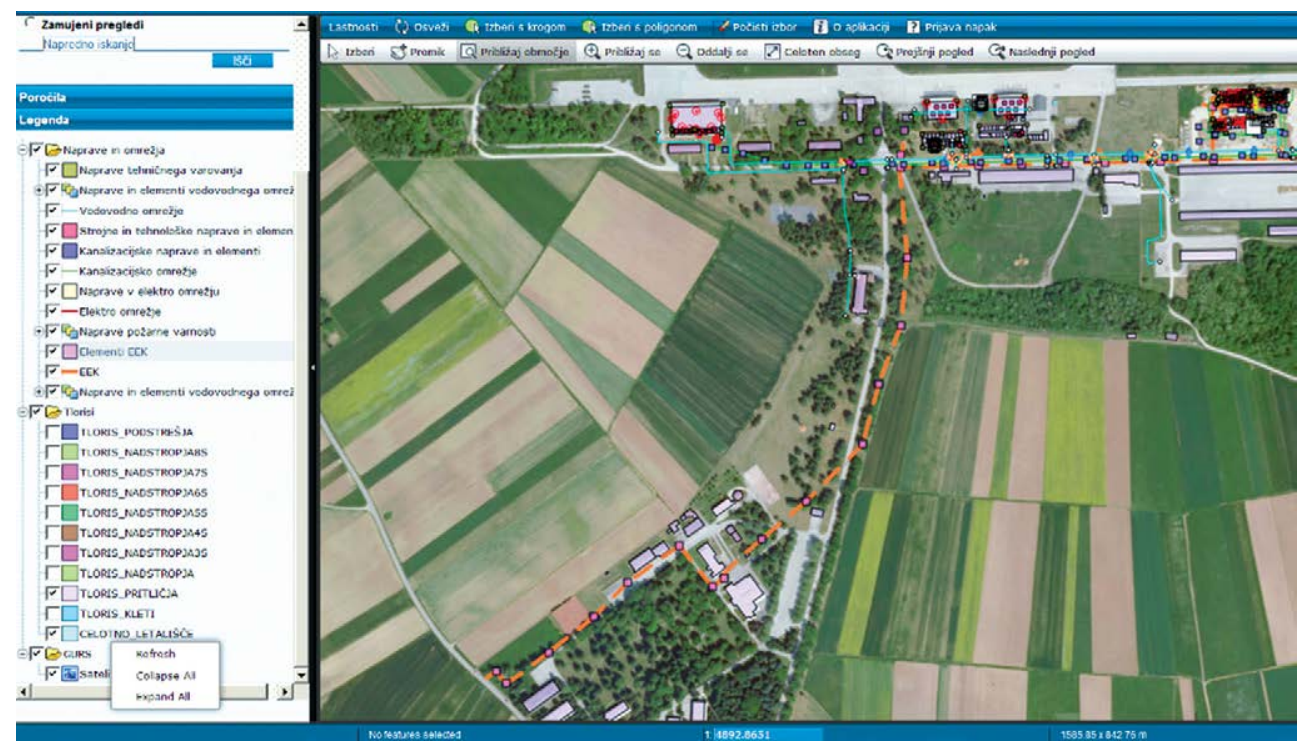

